PROFESSIONAL

\title{
NON-TECHNICAL ATTRIBUTES IN PARAMEDICINE: IS SITUATIONAL JUDGEMENT TESTING THE SOLUTION?
}

\author{
Ryan Bennett BEmergHIth ${ }^{1,2}$, Brett Williams $\mathrm{PhD}^{2^{\star}}$
}

*brett.williams@monash.edu

\section{OPEN ACCESS ARTICLE}

Recommended Citation: Bennett $\mathrm{R}$ and Williams B. Non-technical attributes in paramedicine: Is situational judgement testing the solution? Irish Journal of Paramedicine. 4(1). Jun 2019. https:// doi.org/10.32378/ijp.v4i1.171

Received: 18 Dec 2018

Revised: 20 Mar 2019

Accepted: 25 Mar 2019

Published: 01 May 2019

Copyright: (C) 2019, the authors. This is an Open Access article distributed under the terms of the Creative Commons Attribution-Non-CommercialShare Alike 4.0 International licence which permits use, distribution, and reproduction in any medium provided the original work and any attributes thereof are properly cited, are distributed unde the same licence, and that the work is not used fo commercial purposes.

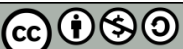

Funding/support: None declared.

Competing interests: None declared.

Provenance and review: Not commissioned, peer-reviewed.

\section{Author affiliations}

1. Ambulance Victoria, Victoria, Australia

2. Dept. of Community Emergency Health and

Paramedic Practice, Monash University,

Victoria, Australia.

\section{Abstract}

\section{Background}

Non-technical attributes have been identified as important and desirable qualities for all paramedics. Despite this, there is currently little research exploring the assessment of non-technical attributes in paramedicine. Situational judgement tests (SJT) have been identified as a valid and reliable assessment of nontechnical attributes in medical education; however, it appears there is no research exploring the use of SJTs in the field of paramedicine. This paper outlines the background information on SJTs, what they are and their successful implementation in medicine. Additionally, this paper identifies potential uses for SJTs in paramedicine including admission and mental health screening based of previous research in medical education. This paper concludes that SJTs could be utilised in the field of paramedicine to measure non-technical attributes.

Keywords: Allied Health Personnel; Non-technical skills; Paramedics; Situational Judgement Tests 


\section{Introduction}

In recent times there has been greater recognition that non-technical attributes such as professionalism, integrity, empathy and communication are critically important predictors of job performance. $(1,2)$ This has been a large area of focus in medical education research over the last 20 years, with arguments claiming that academic and technical ability alone is insufficient to make the transition to a competent clinician.(3) Patterson et al (2016) has demonstrated this through a longitudinal study where the predictive performance of academia decreased through the student's transition from study and into practice.(4)

Non-technical attributes have previously been identified as an important skill set within paramedicine with international sources referring to their importance for practicing as a paramedic.(2) Despite this, there is little evidence within paramedicine on the best way to embed or assess for these attributes. The only study to date investigating the assessment of non-technical skills within paramedicine is through the use of Multiple Mini Interviews (MMI).(2) Tavares and Mausz (2013) conducted a 2-day, 10 station MMI and 10 station simulation-based assessment on final year Canadian paramedic students who had not yet practiced as independent clinicians. The study focussed on several non-technical attributes including communication, teamwork, critical thinking and problem solving. Tavares and Mausz (2013) found that MMI were a reliable and valid measure of non-technical attributes whilst also observing a moderate positive relationship between non-technical attributes and clinical skills. Participants reported neutral opinions to the MMI but reported it would not stop them from applying for paramedic programmes.(2)

Contrary to this, Hissbach et al (2014) have argued that MMI's are not a fair assessment method suggesting results are open to bias from assessors.(5) Additionally, previous research has been inconclusive in supporting the construct validity of MMI assessments and this remains an area for further exploration.(3) This therefore provides some uncertainty and opportunity to explore other methods for the best way to measure non-technical attributes.

Over the last 20 years Situational Judgement Tests (SJT) have emerged as an effective tool at measuring non-technical attributes in medicine and has gained significant popularity in this time; particularly in larger scale assessment processes.(1) SJTs and MMIs have both been proven to have higher predictive validity over character references and personal statements in medicine, whilst SJTs alone have been found to have significant validity in predicting future job performance.(3) Other benefits that SJT have over MMI is they are cost effective, less resource intensive and remove the risk of interviewer bias. $(3,6)$ Currently, it appears that there is no research involving the use of SJTs in the field of paramedicine. Therefore, this paper aims to provide background information on SJTs, what they are, how they have been successfully implemented into medical education and whether SJTs have a place or application in paramedicine.

\section{What are Situational Judgement Tests?}

SJTs are designed to assess an individual's judgement in hypothetical situations, with a goal of assessing interpersonal or non-technical attributes opposed to clinical knowledge. $(1,7)$ They are associated with personality, cognitive ability and job knowledge.(8) Generally, SJTs provide a challenging written situation (vignette) to the individual that they may encounter in their target role.(9) Individuals are then required to identify an appropriate response to this situation from psychometrically tested pre-selected answers. $(1,7)$ It is important to note that SJTs are a measurement methodology opposed to a specific assessment style, as formats and response styles can vary significantly across assessments. $(1,10,11)$

\section{Theory behind SJTs}

SJTs require the candidate to select non-technical traits to display in certain situations, they aim to determine how a person would act, rather than what the individual thinks they should do. SJTs are underpinned by two key behavioural theories (11). These include the long-standing Behavioural Consistency Theory and the growing theory of Implicit Trait Policies (ITP).(12, 13)

Behavioural Consistency Theory postulates that past behaviour is an indicator of 
future behaviour. Thus, assessing a candidate's response to a situation should dictate how they would react to a similar situation in the future.(12) ITP proposes that individuals develop behavioural beliefs and how behaviours/traits are interpreted and perceived in certain situations.(13) Individuals use these beliefs to determine which behaviour to portray in the given moment. ITP theorises that individuals choose a behavioural trait to display as opposed their behavioural tendencies.(13)

\section{Different delivery styles of SJTs}

Generally, SJTs are delivered to the candidate in either written or video-based formats. Written SJTs are conducted where the test taker is presented with a written/text based hypothetical situation vignette. Video-based SJTs require the test taker to watch a video scenario (usually acted out) that targets set non-technical attributes. Both formats require the candidate to determine the appropriate response from pre-selected answers psychometrically developed by subject matter experts.(11, 14)

Written SJTs (see Text box 1 for example) are a more cost-effective option to develop and maintain compared to video SJTs.(11, 15) Furthermore, written SJTs have been found to have a higher cognitive demand than video-based SJTs (15). Patterson et al (2016) argues that this may be beneficial in the setting of "high stakes" environments such as medicine that require a higher-level cognitive thinking.(11) Video-based SJTs have been found to have a higher predictive and incremental validity at measuring nontechnical attributes in comparison to written SJTs.(3, 15) Lievens et al (2006) argues this could be due to the ability to collect information on facial expressions, body language and voice inclinations from video based SJT's, which play a significant role in interpersonal interactions.(15)

Further research has been conducted using alternate delivery methods including computer-based SJTs (16) and iPads (17). Both of these were found to be effective and would further alleviate the resource intensiveness required to score SJTs.

A patient examination is taking place between a physician and patient at a large tertiary hospital; a final year paramedic student is undertaking their clinical placement there and is observing the examination. The physician advises the patient that she needs some further tests to rule out terminal cancer. The physician is urgently called away leaving the paramedic student alone with the patient. The patient is visually distraught and asks the paramedic student what the blood test will show.

How appropriate are the each of the following responses by the paramedic student in this example?

1. Explain to the patient that he is unable to comment on what the tests will show as he is only a paramedic student.

2. Acknowledge the patient's worry and ask whether he would like them to be raised with the physician.

3. Suggest to the patient that he poses these questions to the physician when they return into the room.

4. Advise the patient that he should not worry and that it is unlikely that he will die.

Text box 1. Example of a written-based SJT

Different response styles

An area that has received relatively little research is the effects that response formats have on an SJT.(18) SJTs generally adopt either a knowledge base or behavioural tendency approach to the response instructions.(11) Knowledge base responses require candidates to choose what is the best option in the situation, whereas behavioural tendencies ask the candidate what they are most likely to do in the situation.(19-21) Advantages have been identified for both with behavioural tendencies being more closely aligned to interpersonal and non-technical attributes, whilst knowledge base response 
instructions have been found to be more cognitively involved.(20,22)

Response formats are then determined against a scoring rubric which has been ideally psychometrically designed with subject matter experts.(11) Generally, the scoring rubrics consist of test takers ranking actions in order, rating actions independently, multiple choice or best/worst response.(11) Despite these scoring methods being used regularly, little evidence has been offered into which method has superior psychometric properties.(18) Furthermore, previous research has indicated that small changes to these scoring rubrics have been found to alter the validity and reliability of an SJT significantly. $(11,18)$

Arthur et al (2014) determined that the rate response format was found to have the highest internal consistency and incremental validity when assessed in comparison to the rank and most/least likely in the same SJT.(18) Alternatively, Dore et al (2017) provided candidates with an alternate response method asking candidates to write an open-ended response to the SJT. These results were found to predict candidate personal characteristics with a similar accuracy to the way GPA assess cognitive function.(6) Further research is required to determine the validity in comparison to traditional SJT response formats.

\section{Student Perceptions}

SJTs have been introduced into medical school admissions and have also been piloted for the use in dentistry. $(7,24)$ Evidence from these studies suggests that candidates found SJT assessments to be fair and appropriate whilst maintaining a high face validity.(7, 23, 24) Furthermore, Lievens (2013) found from post SJT questionnaires that candidates felt that SJTs were more relevant to the profession and less difficult in comparison to other cognitive assessments.(24) Goss et al (2017) additionally documented that SJTs conducted in Australia raised awareness to learners of the issues new doctors may face in the workplace.(25) These preliminary results suggest that SJTs are perceived well by candidates and may provide workplace context to questions and situations the learners are yet to face through their studies.

\section{Are SJT's Fair?}

Fairness of selection criteria has become heavily discussed within medical education as health service providers such as hospitals are required to select candidates that meet the job requirements while also promoting diversity within the applicant pool.(11). Literature indicates that females tend to score higher on SJTs compared with males $(11,23)$ which is consistent with other non-academic assessments.(11) Lievens (2013) supported this, finding that females performed higher in non-technical SJT whereas males performed higher in cognitive SJTs.(24) Despite these gender differences, Lievens (2013) identified SJTs appear to have low adverse effects on ethnicity, suggesting the use of SJTs may attract a wider ethnicity of candidates, hence increasing the ethnic demographic.(24)

\section{How would SJTs benefit paramedicine?}

Previous medical literature has proven SJTs to be reliable and valid, testing multiple interpersonal characteristics including professionalism, integrity, communication, resilience and emotional intelligence. $(8,26-28)$ These non-technical qualities are critical attributes for paramedics and are important domains in paramedic education and accreditation requirements. $(2,29-33)$ Therefore, it would be a reasonable assumption that paramedicine could benefit from utilising SJTs in measuring non-technical attributes. However, this has not been empirically explored in the paramedicine sector. Fortunately, the empirical work undertaken by medical education has offered insight into some of the uses of SJT. These uses have been summarised below along with the implications for the field of paramedicine.

\section{Admission Screening}

SJTs have successfully and reliably proven to predict job performance and training outcomes in medicine when used in conjunction with an educational performance measure. $(13,34)$ As such, SJTs have become increasingly more popular over the last decade for use in health care selection in the UK along with medical admissions in Belgium and Australia.(11, 24, 25) Within ambulance services, pre-employment and 
course enrolment screening of candidate suitability is generally a difficult task. This creates a "bottle-neck" effect on university graduates all bidding for limited graduate paramedic positions at the conclusion of their studies. Given the previous success of SJT screening in medicine, the authors argue there could be benefit from adopting a similar approach in paramedicine to limit the resource intensive nature of applicant screening. Furthermore, SJTs offer a fair, reliable and valid pre-employment screening tool to ensure applicants possess the appropriate non-technical attributes to perform in the role of a paramedic prior to admission into the job.

\section{Mental Health}

Mental health issues are a growing concern within the field of paramedicine and it has been proven the negative effects that health care work can have on an individual's health. (8) SJTs have been used in multiple medical studies to explore the effects of mental health. $(8,26)$ Pangallo et al $(2016)$ explored the use of resilience (which has been linked to increased mental health and wellbeing) in palliative care workers.(8) Pangallo et al (2016) found excellent reliability and predictive validity of SJTs in measuring resilience levels in palliative care workers. Research has also been conducted through the use of SJTs to determine the relationship between emotional intelligence and wellbeing. The findings indicating those who have higher emotional management had a higher psychological wellbeing.(26)

Although mental health research through the use of SJTs appears limited, it is evident that previous research has supported SJTs as a successful tool at assessing and identifying mental health indicators. This provides opportunity in the field of paramedicine, where SJTs could be utilised to screen the current or incumbent workforce for risk factors (such as resilience) to identify at risk behaviours or traits. This would mean that at risk individuals could be identified, monitored and receive assistance earlier rather than later, improving overall workforce wellbeing and mental health.

\section{Assessing and teaching non-technical skills}

Another potential utilisation of SJTs is to determine whether they can measure the teaching of non-technical attributes in the setting of paramedicine. Medical education has previously found SJTs to successfully determine multiple non-technical attributes within medicine. Thus, SJT's could be used in the assessment of pre and post paramedical studies of particular non-technical attributes such as empathy, teamwork etc. The results could then be used to determine whether these non-technical attributes are being taught or developed at tertiary education institutions, or inherently already possessed by students prior to arrival to university. This would assist in determining the effectiveness of current course curricula and graduate outcomes whilst identifying key areas for development. Additionally, the results could help shape future university curricula and learning outcomes to incorporate teaching/development of non-technical skills.

The HCPC and wider UK health department have been investigating ways to measure professionalism within paramedicine.(35) SJT's could be utilised to measure and address an individual's understanding of professional behaviour. This could provide organisations information about the workforce to help determine workplace learning needs, helping to shape future workplace training.

\section{Conclusion}

The use of SJTs in medical education has occurred for over 20 years. In this time, they have been found to be a valid and reliable assessment tool at predicting non-technical attributes and future job performance. It appears there is currently no research investigating the assessment of non-technical attributes using SJTs in paramedicine. Future work is needed to examine if SJTs are valid and reliable in paramedicine; if so, they could change the way applicants are selected, improve mental health and wellbeing and also change the shape of future education.

\section{References}

1. Patterson F, Ashworth V, Zibarras L, Coan P, Kerrin M, O'Neill P. Evaluations of situational judgement tests to assess non-academic attributes in selection. Medical education. 2012;46(9):850-68. https://doi.org/10.1111/j.1365-2923.2012.04336.x 
2. Tavares W, Mausz J. Assessment of non-clinical attributes in paramedicine using multiple mini-interviews. Emerg Med J. 2015;32(1):70-5. https://doi.org/10.1136/ emermed-2013-202964

3. Patterson F, Knight A, Dowell J, Nicholson S, Cousans F, Cleland J. How effective are selection methods in medical education? A systematic review. Medical education. 2016;50(1):36-60. https://doi.org/10.1111/medu.12817

4. Patterson F, Rowett E, Hale R, Grant M, Roberts C, Cousans F, et al. The predictive validity of a situational judgement test and multiple-mini interview for entry into postgraduate training in Australia. BMC Med Educ. 2016; 16:87. https://doi.org/10.1186/s12909-016-0606-4

5. Hissbach JC, Sehner S, Harendza S, Hampe W. Cutting costs of multiple miniinterviews - changes in reliability and efficiency of the Hamburg medical school admission test between two applications. BMC Med Educ. 2014; 14:54. https:// doi.org/ 10.1186/1472-6920-14-54.

6. Dore KL, Reiter HI, Kreuger S, Norman GR. CASPer, an online pre-interview screen for personal/professional characteristics: prediction of national licensure scores. Adv Health Sci Educ Theory Pract. 2017;22(2):327-36. https:// doi.org/10.1007/s10459-016-9739-9

7. Rowett E, Patterson F, Cousans F, Elley K. Using a situational judgement test for selection into dental core training: a preliminary analysis. Br Dent J. 2017;222 (9):715-9. https://doi.org/10.1038/sj.bdj.2017.410

8. Pangallo A, Zibarras L, Patterson F. Measuring resilience in palliative care workers using the situational judgement test methodology. Medical education. 2016;50(11):1131-42. https://doi.org/10.1111/medu.13072

9. Cousans F, Patterson F, Edwards H, Walker K, McLachlan JC, Good D. Evaluating the complementary roles of an SJT and academic assessment for entry into clinical practice. Adv Health Sci Educ Theory Pract. 2017;22(2):401-13. https://doi.org/10.1007/s10459-017-9755-4

10. Lievens F, Peeters H, Schollaert E. Situational judgement tests: a review of recent research. Pers Rev. 2008;37(4):426-41. https:// doi.org/10.1108/00483480810877598

11. Patterson F, Zibarras L, Ashworth V. Situational judgement tests in medical education and training: Research, theory and practice: AMEE Guide No. 100. Med Teach. 2016;38(1):3-17. https://doi.org/10.3109/0142159X.2015.1072619

12. Wernimont PF, Campbell JP. Signs, samples, and criteria. The Journal of applied psychology. 1968;52(5):372-6. https://doi.org/10.1037/h0026244

13. Motowidlo SJ, Hooper AC, Jackson H. Implicit policies about relations between personality traits and behavioral effectiveness in situational judgement items. The Journal of applied psychology. 2006;91(4):749-61. https://doi.org/10.1037/00219010.91.4.749

14. Lievens F, Sackett PR. Situational judgment tests in high-stakes settings: issues and strategies with generating alternate forms. The Journal of applied psychology. 2007;92(4):1043-55. https://doi.org/10.1037/0021-9010.92.4.1043

15. Lievens F, Sackett PR. Video-based versus written situational judgment tests: a comparison in terms of predictive validity. The Journal of applied psychology. 2006;91(5):1181-8. https://doi.org/10.1037/0021-9010.91.5.1181

16. Kiessling C, Bauer J, Gartmeier M, Iblher P, Karsten G, Kiesewetter J, et al. Development and validation of a computer-based situational judgement test to assess medical students' communication skills in the field of shared decision making. Patient Educ Couns. 2016;99(11):1858-64. https://doi.org/10.1016/ j.pec.2016.06.006

17. Colbert-Getz JM, Pippitt K, Chan B. Developing a situational judgment test blueprint for assessing the non-cognitive skills of applicants to the University of Utah School of Medicine, the United States. Journal of educational evaluation for health professions. 2015; 12:51. https://doi.org/10.3352/jeehp.2015.12.51

18. Arthur W, Glaze RM, Jarrett SM, White CD, Schurig I, Taylor JE. Comparative evaluation of three situational judgment test response formats in terms of construct-related validity, subgroup differences, and susceptibility to response distortion. The Journal of applied psychology. 2014;99(3):535-45. https:// 
doi.org/10.1037/a0035788

19. McDaniel M, Hartman N, Grubb W. Situational judgment tests, knowledge, behavioral tendency and validity: A meta-analysis. 18th Annual Conference of the Society for Industrial Organizational Psychology Orlando. 2003. http:// citeseerx.ist.psu.edu/viewdoc/download? doi $=10.1 .1 .728 .3210 \&$ rep $=$ rep $1 \&$ type $=$ pdf

20. McDaniel M, Hartman N, Whetzel D, Grubb W. Situational judgment tests, response instructions, and validity: A meta-analysis. Pers Psychol. 2007;60(1):6391. https://doi.org/10.1111/j.1744-6570.2007.00065.x

21. McDaniel M, Nguyen N. Situational judgment tests: A review of practice and constructs assessed. Int J Sel Assess. 2001;9(1/2):103-13. https:// doi.org/10.1108/00483480810877598

22. Whetzel D, McDaniel M. Situational judgment tests: An overview of current research. Hum Resour Manag Rev 2009;19(3):188-202. https://doi.org/ 10.1016/ j.hrmr.2009.03.007

23. Patterson F, Ashworth V, Mehra S, Falcon H. Could situational judgement tests be used for selection into dental foundation training? British Dental Journal. 2012;213(1):23-6. https://doi.org/10.1038/sj.bdj.2012.560

24. Lievens F. Adjusting medical school admission: assessing interpersonal skills using situational judgement tests. Medical education. 2013;47(2):182-9. https:// doi.org/10.1111/medu.12089

25. Goss BD, Ryan AT, Waring J, Judd T, Chiavaroli NG, O'Brien RC, et al. Beyond Selection: The Use of Situational Judgement Tests in the Teaching and Assessment of Professionalism. Academic medicine: journal of the Association of American Medical Colleges. 2017;92(6):780-4. https://doi.org/10.1097/ ACM.0000000000001591

26. Burrus J, Betancourt A, Holtzman S, Minsky J, MacCann C, Roberts RD. Emotional Intelligence Relates to Well-Being: Evidence from the Situational Judgment Test of Emotional Management. Applied psychology Health and wellbeing. 2012;4(2):151-66. https://doi.org/10.1111/j.1758-0854.2012.01066.x

27. Schubert S, Ortwein H, Dumitsch A, Schwantes U, Wilhelm O, Kiessling C. A situational judgement test of professional behaviour: development and validation. Med Teach. 2008;30(5):528-33. https://doi.org/10.1080/01421590801952994

28. De Leng WE, Stegers-Jager KM, Born MP, Themmen APN. Integrity situational judgement test for medical school selection: judging 'what to do' versus 'what not to do'. Medical education. 2018;52(4):427-37. https://doi.org/10.1111/ medu. 13498

29. Health Professional Council of South Africa. Professional Board for Emergency Care: Emergency Care Assistant. Pretoria, South Africa: HPCSA; 2016.

30. College of Paramedics. Paramedic Curriculum Guidance. 3rd ed. Bridgwater, UK: College of Paramedics; 2014;7-10. Available from: https:// www.collegeofparamedics.co.uk/downloads/Curriculum_Guidance_2014.pdf

31. Paramedic Association of Canada. National Occupational Competency Profile for Paramedic Association of Canada. October 2011. Available from: http:// www.paramedic.ca/uploaded/web/documents/2011-10-31-Approved-NOCPEnglish-Master.pdf.

32. Council of Ambulance Authorities Inc. Professional Competency Standards Paramedics. 2010;1-18. Available from: www.caa.net.au/images/documents/ accreditation_resources/

Paramedic_Professional_Competency_Standards_V2.2_February_2013_PEPAS.p df.

33. Pre-Hospital Emergency Care Council. 2014. Paramedic Education and Training Standard-V1. Available from: https://www.phecit.ie/Images/PHECC/Career\% 20and $\% 20$ Education/Education $\% 20$ Standards/STN015\%20-Paramedic $\%$ 20Education\%20and\%20Training\%20Standard-V1.pdf.

34. Lievens F, Patterson F. The validity and incremental validity of knowledge tests, low-fidelity simulations, and high-fidelity simulations for predicting job performance in advanced-level high-stakes selection. The Journal of applied psychology. 2011;96(5):927-40. https://doi.org/10.1037/a0023496 
35. van der Gaag A, Donaghy J. Paramedics and professionalism: Looking back and looking forwards. Journal of Paramedic Practice. 2013, 5(1): 8-10. https:// doi.org/10.12968/jpar.2013.5.1.8 